\title{
A TECHNIQUE FOR OBSERVING THE BEHAVIOUR OF SMALL ANIMALS UNDER FIELD CONDITIONS*
}

\author{
By Michael H. Robinson and Nicholas D. E. Smythe \\ Smithsonian Tropical Research Institute \\ P.O. Box 2072, Balboa, Panama Canal Zone
}

Small animals are difficult to observe under field conditions, and arthropods of less than $10 \mathrm{~mm}$ body length are particularly difficult subjects. When such animals are making complex movements with small parts of their body (mouth parts, reproductive organs) some device is needed to augment direct vision. One solution to the problem is to use the zoom optics of a movie camera equipped with close-up devices (Robinson \& Robinson, 1972). Recently, however, one of us (M.H.R.) studied the behaviour of Drosophila-sized flies that associate with orb-web spiders and spend long periods standing on the spider's body. To find out what the flies were doing there it was essential to see them in close-up and be able to watch them, for long periods, under field conditions. Watching them through the macrosystem of a movie camera gave insufficient magnification. We solved the problem by adapting a stereo-binocular microscope for horizontal viewing. We feel that this adaptation has a wide variety of potential applications in field ethology. It may be a re-invention but is worth describing here.

\section{Making the Microscope Adapter}

Essentially the adaptation consists of making a mount that enables the microscope to be used on a camera tripod, for horizontal viewing and with a greatly extended focussing range. Any microscope can be used that consists of a subassembly comprising the optical and focussing systems that is clamped onto a vertical column on the base subassembly. The optical/focussing subassembly is simply detached from the conventional base and attached to a specially made horizontal column mounted on a tripod. All that is needed is a length of steel rod the same diameter as the support column on the original base. The rod has then to be modified to fit onto a tripod. This can be done in several ways depending on

\footnotetext{
*Manuscript received by the editor September 7, 1976.
} 
the degree of engineering sophistication that is available. Two methods are shown in Figure 1; many others are perfectly feasible. The length of the rod determines the extent of the coarse focussing that is made possible by simply sliding the microscope assembly along the rod before using the rack-and-pinion focussing of the subassembly. Unwelcome vibrations may occur if too long a rod is used.
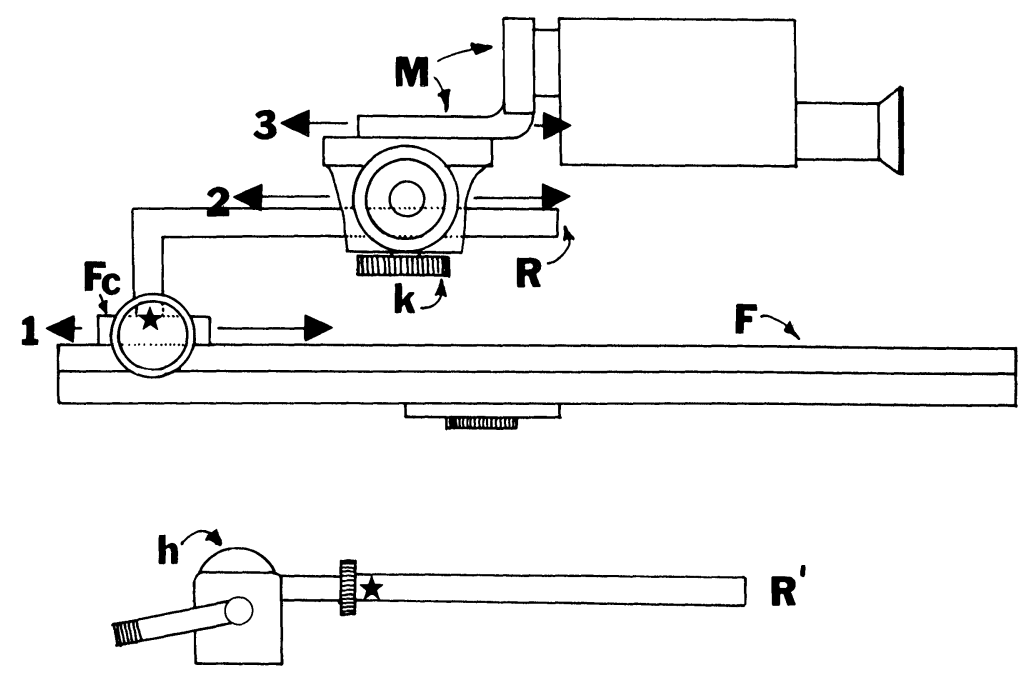

EXPLANATION OF FIGURE

1, 2 and 3. *arrowed: focussing facilities. 1. Focussing available on camera focussing rail (F). 2. Focussing available on microscope mounting rod (R); this is obtained by slackening knob $(\mathrm{k})$ that normally attaches microscope to its stand. 3. Focussing available by rack-and-pinion focussing of microscope subunit (M).

Two methods of mounting microscope carrying rod to tripod are shown. In main diagram, $R$ is bent at right angles and the starred end is drilled and tapped to take the standard camera attachment bolt on the focussing rail at $\mathrm{Fc}$. The detail below shows an alternative: $R^{\prime}$, a straight rod, is drilled and tapped to attach to a ball-and-socket camera mount $(\mathrm{h})$ that attaches at $\mathrm{Fc}$. 
We find that even greater flexibility of use is possible if the microscope is attached to a rod carried on a photographic focussing rail rather than one directly attached to a tripod head. With an extralong focussing rail ( $45 \mathrm{~cm}$, for instance) it is possible to put the tripod down once, close to the subject, and be sure that enough focussing range is available to bring the subject in focus without again moving the tripod. This can be critical in circumstances where movements of the vegetation in which the tripod is standing can cause the subject to flee or cease normal activity.

Using the device requires practice. A wide variety of adjustments are available through the pan-and-tilt head of the tripod, and through the rack-and-pinion of the focussing rail and microscope focussing system. Use of a tripod with an elevator head that is reversible further extends the scope of the device. Depth of field is slight even at very low powers of the microscope but continual focus adjustment is not difficult or distracting. Viewing with one's hands resting on the focussing wheels of the microscope helps one to acquire a habit of keeping a moving object in focus. It is possible to use one eyepiece for viewing and have a camera permanently attached to the other. This helps immensely in obtaining action photographs of transitory behavioural events.

\section{REFERENCES}

Robinson, M. H., AND Robinson, B.

1972. Techniques for the observation of spider behaviour. Bull. Brit. Arach. Soc. 2:58-59. 

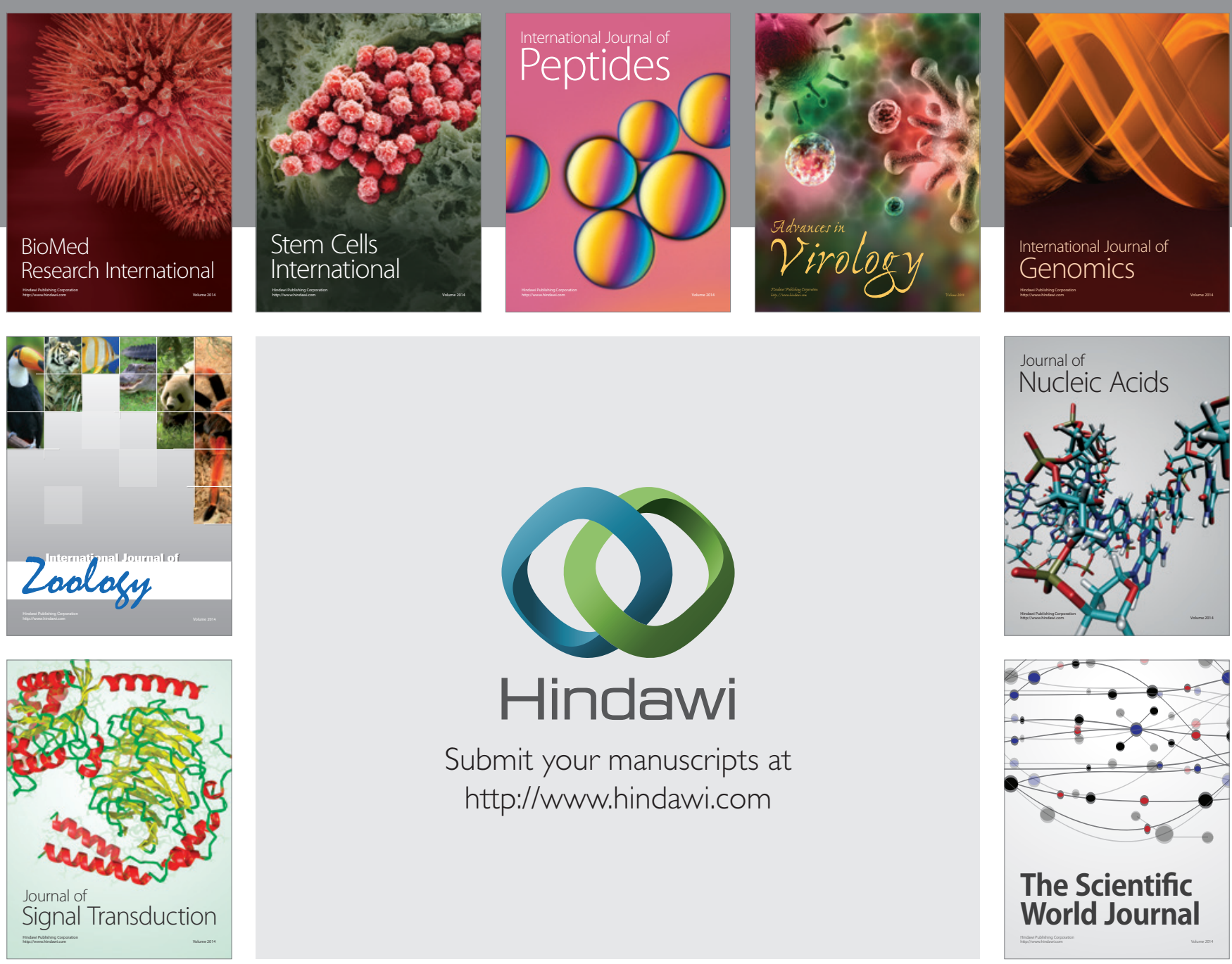

Submit your manuscripts at

http://www.hindawi.com
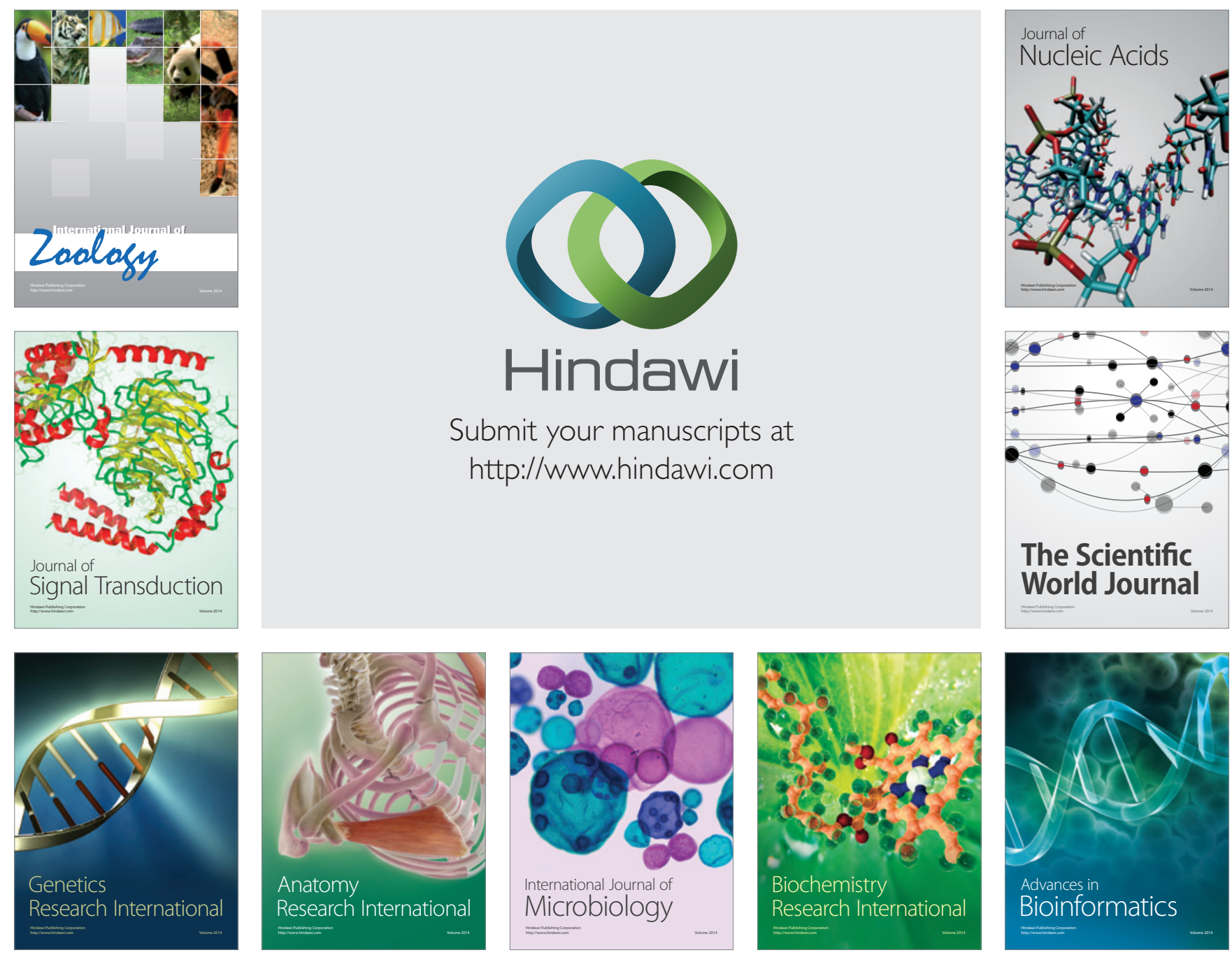

The Scientific World Journal
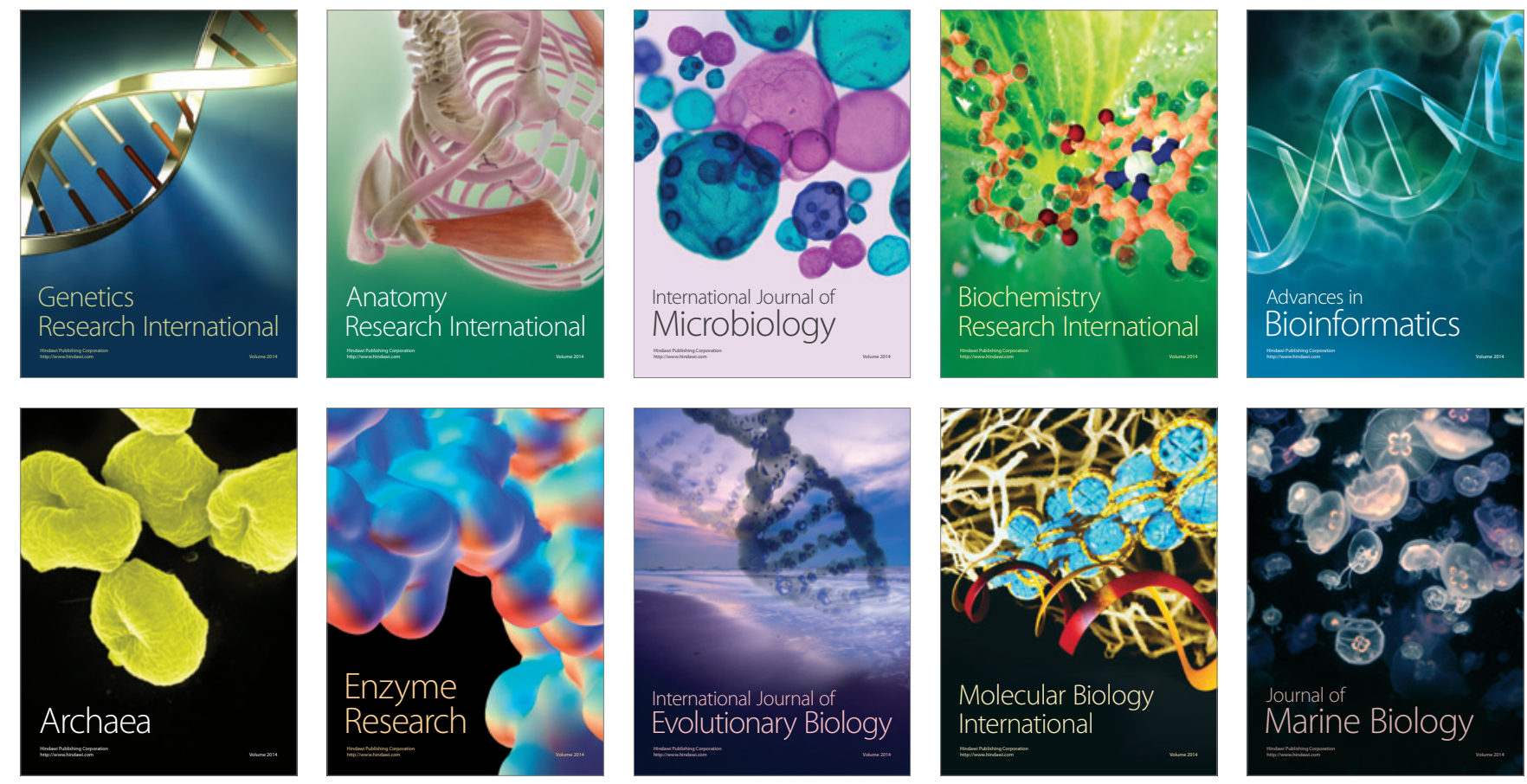